\title{
Sensitization of the Locomotor Response to Psychostimulants after Repeated Opiate Exposure: Role of the Nucleus Accumbens
}

\author{
S.T. Cunningham, Ph.D., Marianne Finn, B.A., and Ann E. Kelley, Ph.D.
}

The following experiments were performed to ascertain the role of the nucleus accumbens in opiate-dopamine interactions using measures of locomotor activity. Three separate experiments were carried out. In Experiment 1, rats received systemic morphine (10 $\mathrm{mg} / \mathrm{kg} I P)$ or saline (1 $\mathrm{ml} / \mathrm{kg} I P$ ) every other day for 5 days, followed by systemic amphetamine $(1.5 \mathrm{mg} / \mathrm{kg}) 48$ hours following the fifth injection. Animals in the morphine pretreatment group exhibited a sensitized locomotor response to amphetamine. In Experiment 2, animals received the same systemic pretreatment and were subsequently given intraaccumbens saline, amphetamine $(2.5 \mu \mathrm{g} / 0.5 \mu \mathrm{l})$ or cocaine $(7 \mu \mathrm{g} / 0.5$ $\mu l)$, each separated by 48 hours. Morphine-pretreated animals showed enhanced motor activity in response to

KEY WORDS: Locomotor activity; Nucleus accumbens; Morphine; d-Amphetamine; Cocaine; Sensitization

Opiate-dopamine interactions have been studied in a number of behavioral paradigms. For example, there is ample evidence in the literature that preexposure to opiates results in an augmented locomotor response to subsequent treatment with stimulants such as cocaine or am-

From the Institute of Animal Behavior (STC), The State University of New Jersey, Newark, NJ; the Department of Psychology (MF), The University of Connecticut, Storrs, CT; and the Department of Psychiatry (AEK), University of Wisconsin-Madison Medical School, Madison, WI.

Address correspondence to: Dr. Ann E. Kelley, Department of Psychiatry, University of Wisconsin-Madison Medical School, 2671 Medical Science Center, 1300 University Avenue, Madison, WI 53706.

Received February 22, 1996; revised May 27, 1996; accepted June 10, 1996 . intraaccumbens microinfusion of the psychostimulant drugs. Finally, in Experiment 3, multiple microinjections of morphine $(0.5 \mu \mathrm{g} / 0.5 \mu \mathrm{l})$ directly into the nucleus accumbens resulted in a potentiated locomotor response to intraaccumbens amphetamine $(2.5 \mu \mathrm{g} / 0.5 \mu \mathrm{l})$. These data indicate that the nucleus accumbens may contribute to both the development and expression of opiate-stimulant crosssensitization. The neural basis of this sensitization is hypothesized to be a common intracellular pathway affected by both classes of drugs, such as the cyclic adenosine monophosphate (AMP) system. (C) 1997 American College of Neuropsychopharmacology [Neuropsychopharmacology 16:147-155, 1997]

phetamine (Kalivas 1985; DuMars et al. 1988; Vezina et al. 1989; Vezina and Stewart 1990). In addition, researchers also have shown that prior treatment with opiates potentiates stimulant-induced responses in reward-related paradigms, such as place preference and conditioned reinforcement (Lett 1989; Bilsky et al. 1992; Cunningham and Kelley 1992).

Much behavioral evidence implicates the ventral tegmental area (VTA) as a substrate for opiate-dopamine cross-sensitization. For example, repeated microinjection of enkephalin or opiates into the VTA causes a progressive increase in the locomotor response and also results in enhanced activation following systemic psychostimulant challenge (Kalivas et al. 1983, 1985; Vezina et al. 1987; DuMars et al. 1988). It is likely that the nucleus accumbens may also be involved in opiate-dopamine cross-sensitization, although few behavioral studies have addressed this question. Anatomical studies indicate that endoge- 

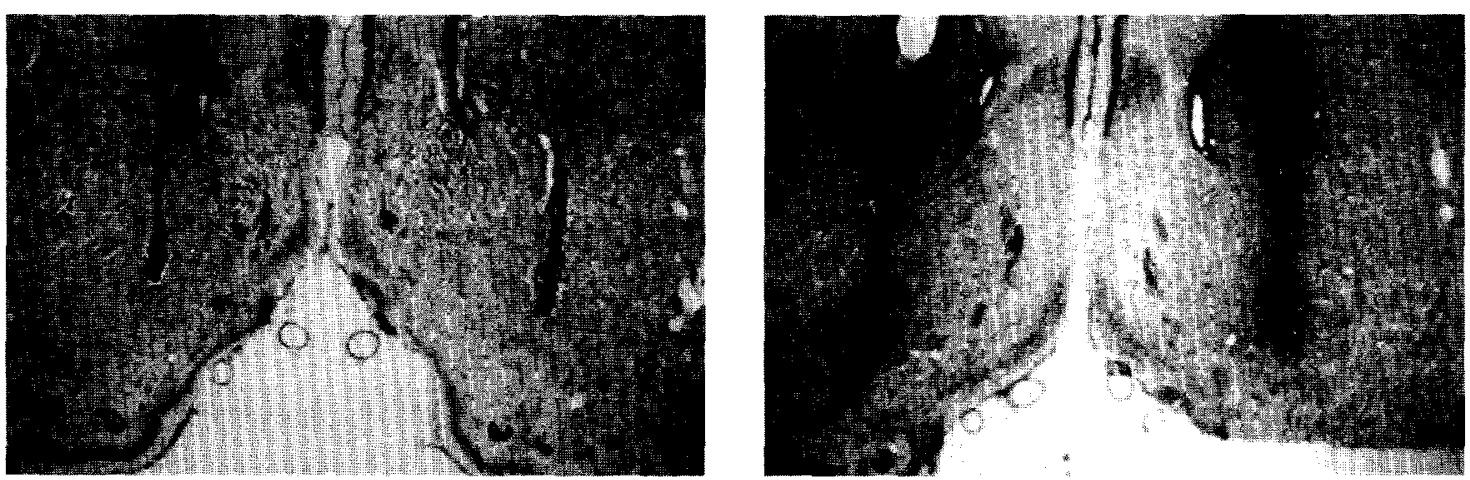

Figure 1. Cannula and injection track location in the nucleus accumbens. (A) Animal from Experiment 2. (B) Animal from Experiment 3. As noted the stereotaxic coordinates were not aimed specifically at "core" or "shell" subregions in these experiments. Most placements were localized approximately at the core-shell border or in the core.

nous enkephalins and their receptors are localized in association with the mesolimbic dopamine system, suggesting a modulatory role for opiates in dopaminergic function (Goodman et al. 1980; Johnson et al. 1980; Pickel et al. 1980; Bouyer et al. 1984; Mansour et al. 1987). Moreover, alterations in striatal dopamine neurotransmission, metabolite production and $\mathrm{G}$ protein-second messenger activity have been reported following opiate manipulations (Kalivas et al. 1983; Di Chiara and Imperato 1988; Pentney and Gratton 1991; Terwilliger et al. 1991; Nestler 1994). In particular, changes in dopamine turnover within the nucleus accumbens have been demonstrated in parallel with sensitized locomotor effects of morphine treatment (Kalivas et al. 1983; Kalivas and Duffy 1988; see Kalivas and Stewart 1991 for review). Therefore, as neurochemical changes are observed within the nucleus accumbens, it is possible that this region may be involved in the expression, and perhaps the development, of behavioral sensitization.

Several studies have suggested that the nucleus accumbens participates in the expression of sensitization; for example, behavioral sensitization to intraaccumbens amphetamine has been described 21 days following a chronic systemic regimen with amphetamine (Paulson and Robinson 1991) and several days following repeated intra-VTA amphetamine injections (Cador et al. 1995). Although the latter study clearly demonstrated the lack of involvement of the accumbens in the induction of amphetamine sensitization, our previous work has suggested that sensitization may be induced by multiple intraaccumbens opiate injections. In an investigation of opiate-dopamine cross-sensitization, we reported that intraaccumbens pretreatment with morphine resulted in potentiated amphetamine-induced responding for conditioned reward (Cunningham and Kelley 1992). The present study was designed to further investigate the direct involvement of the nucleus accumbens in the development of opiate-dopamine cross-sensitization in a locomotor activity paradigm.

\section{MATERIALS AND METHODS}

\section{Animals and Surgery}

A total of 42 male Sprague-Dawley rats (Charles River Laboratories, Wilmington, MA) was used for the following experiments. Food and water were available ad libitum, and the animals were housed in pairs on a 12 hour light-dark cycle. All behavioral testing was carried out between 0900 and $1700 \mathrm{~h}$.

A few days after arrival, animals were anesthetized with sodium pentobarbital $(50 \mathrm{mg} / \mathrm{kg} \mathrm{IP})$ and given atropine $(0.54 \mathrm{mg} / \mathrm{kg} \mathrm{SC})$ for surgical procedures. Animals were placed in a Kopf stereotaxis for implantation of stainless 23-gauge steel cannula guides. Based on the atlas of Pellegrino and Cushman (1967) with incisor bar 5 $\mathrm{mm}$ above interaural zero, the coordinates were (in $\mathrm{mm}$ ): anteroposterior +3.5 from bregma; mediolateral \pm 1.7 from midline; and dorsoventral -5.7 from the skull surface. The cannulae $(10 \mathrm{~mm})$ were aimed at the nucleus accumbens and affixed to skull screws with liquid acrylic and light-curable dental resin (Dental Supply Co. of New England, Boston, MA). At the end of surgery, wire stylets were placed in the cannulae to prevent occlusion, and animals were allowed a minimum recovery period of 2 to 3 days.

\section{Drugs and Microinfusion}

Morphine sulfate (Penick Corp., Lyndhurst, $\mathrm{NJ}$ ) $d$-amphetamine sulfate (Sigma Chemical Co., St. Louis, MO), and cocaine hydrochloride (Sigma) were dissolved in $0.9 \%$ isotonic sterile saline. Systemic injections were given IP. For microinjections, stainless 30 -gauge steel injector needles $2.5 \mathrm{~mm}$ longer than indwelling cannulae, were used to infuse the drugs bilaterally. A microdrive pump (Harvard Apparatus), connected to the injectors via polyethylene tubing (PE-10, Clay Adams), delivered the drugs over 1 minute and 33 seconds with a 1-minute diffusion 
A.

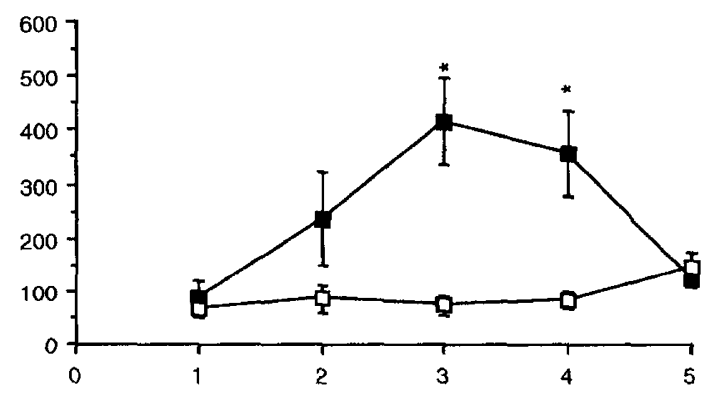

B.

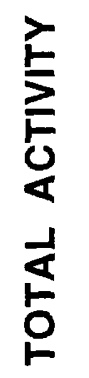

\section{Behavioral Apparatus}

Fifteen plastic cages with wire grid floors were used to measure locomotor activity. A total of six infrared photocells were situated along each cage; two photocells along the horizontal axis recorded locomotor activity, and four photocells placed at the top of the cage recorded rearing. All photocells were interfaced to a microprocessor (Stimtek, Arlington, MA) that recorded the total number of photobeam breaks every 10 minutes. Animals were habituated to these activity cages for 2 hours (postoperatively), and for 1 hour before each test procedure.

\section{Experimental Design}

All doses and drug regimens for the current experiments were chosen based on preliminary data and the existing literature. Dose-response curves were assessed for both the induction and the expression of the behavioral effect. Following all pretreatment regimens and subsequent stimulant challenges, animals were placed in the test apparatus for 2 hours.

\section{Experiment 1}

Thirteen rats were pretreated with five intermittent (every 48 hours) morphine $(n=6,10 \mathrm{mg} / \mathrm{kg}$ ) or saline $(n=$ 7) systemic injections. Forty-eight hours after the final morphine or saline injection, animals were administered amphetamine $(1.5 \mathrm{mg} / \mathrm{kg} \mathrm{IP})$, following the same behavioral procedure. The choice of "withdrawal" period (i.e., the time between the end of repeated treatment and the sensitization test) was based on evidence that behavioral sensitization can be observed 2 days after the end of chronic treatment (Stewart and Vezina 1989; Vezina and Stewart 1989). However, it should be noted that maximal sensitization, as well as more robust neuronal changes, may be observed 2 to 3 weeks following treatment (Paulson and Robinson 1995; Pierce and Kalivas 1995; Pilotte et al. 1996).

\section{Experiment 2}

In this experiment, a total of 14 rats were given five intermittent peripheral treatments with morphine $(n=9)(10$ $\mathrm{mg} / \mathrm{kg})$ or saline $(n=5)$ every 48 hours. Forty-eight hours following the last IP injection, animals were given intraaccumbens microinfusions of saline $(0.5 \mu \mathrm{l})$, amphetamine $(2.5 \mu \mathrm{g} / 0.5 \mu \mathrm{l})$ and cocaine $(7 \mu \mathrm{g} / 0.5 \mu \mathrm{l})$, each separated by 48 hours. These were given in a counterbalanced order over the test days.

\section{Experiment 3}

For this experiment, a total of 15 rats were used. Nine rats received four morphine injections $(0.5 \mu \mathrm{g} / 0.5 \mu \mathrm{l})$ in time. A preliminary saline infusion was given to animals implanted with cannulae to familiarize them with the procedure. For all microinjections, a volume of 0.5 $\mu l$ (per side) was infused. 
A.

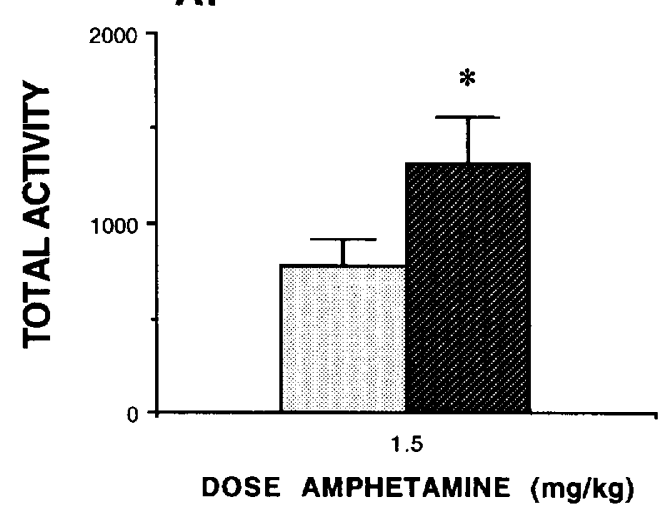

B.

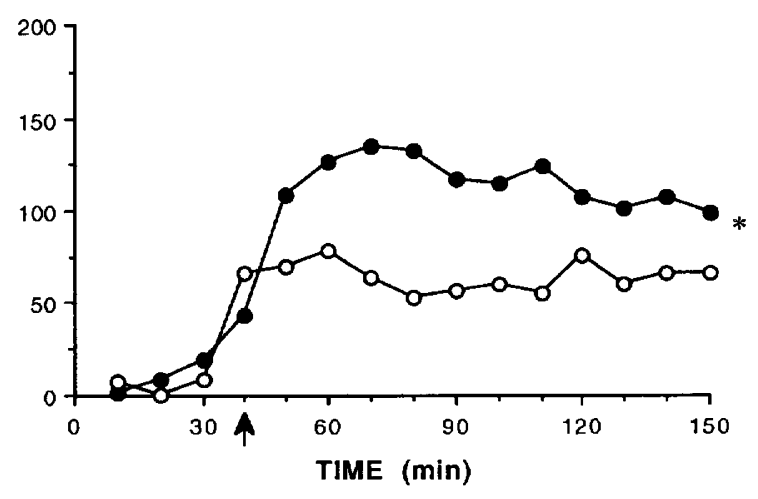

Figure 3. Locomotor response to systemic amphetamine challenge in animals pretreated with IP saline $(n=7)$ or IP morphine $(n=6,10 \mathrm{mg} / \mathrm{kg})$. (A) Total motor response to amphetamine $(1.5 \mathrm{mg} / \mathrm{kg} \mathrm{IP})$ over a 2-hour period. Bars represent mean activation per group \pm SEM. Grey bar, saline pretreatment. Cross-hatched bar, morphine pretreatment. ${ }^{*} p<.05$, between-groups effect. (B) Time course of motor-activating effects of systemic amphetamine. ${ }^{*} p<.05$, group-by-time interaction. Each circle represents mean horizontal activity for that time point. The first three time points indicate the last 30 minutes of habituation prior to amphetamine challenge (arrow indicates first 10-minute period following amphetamine). Open circles, saline. Closed circle, morphine.

the nucleus accumbens, and six rats received four intraaccumbens saline infusion. Two days following the end of pretreatment, a localized injection of amphetamine $(2.5 \mu \mathrm{g} / 0.5 \mu \mathrm{l})$ was given directly into the nucleus accumbens of all animals.

\section{Data Analysis}

All data analyses were done with the aid of an IBMcompatible statistical program (Crunch Interactive Statistical Package). Following a within-subjects analysis of variance of the pretreatment data, means comparisons (orthogonal contrasts) were used to compare differences between pretreatment days within a group. The Student's $t$-test was used to compare between-group means (morphine- and saline-treated groups) on the different pretreatment days. A two-factor (group and time, with repeated measures for time), between-subjects analysis of variance (ANOVA) was performed to analyze locomotor differences between groups on challenge day(s). If any violation of the FMAX test of homogeneity of variance was found, a square root transformation of the data was performed (Bruning and Kintz 1987).

\section{Histology}

To verify cannulae locations, subjects were given an overdose of pentobarbital (75-80 mg/ kg IP) and perfused transcardially by $10 \%$ formalin. Following in situ fixation, the brains were then placed in formalin (minimum 3 days), and coronal cross-sections $(60 \mu \mathrm{m})$ were made and stored on slides. Hand-drawn reconstructions or photomicrographs of these sections were made. Two representative photographs of Nissl-stained sections through the accumbens are shown in Figure 1. The studies described below were not designed with the aim of distinguishing between "core" and "shell" subdivisions of the accumbens; the majority of placements should be considered to be in the core or on the core-shell border.

\section{RESULTS}

All data for locomotor (horizontal) activity are reported in the following, and only those data for vertical activity (rearing) that reached statistical significance are included.

\section{Experiment 1: Effect of Systemic Morphine Pretreatment on Amphetamine-Induced Motor Activation}

Repeated peripheral administration of morphine resulted in progressively greater activation over the first few days followed by a diminution in motor response on subsequent days. An ANOVA of the morphine pretreatment data revealed a significant effect of day $(F[4,28]=6.09, p<.01)$. Post hoc analysis indicated that the locomotor response in the morphine group was significantly greater on Days 3 and 4 as compared to Days 1 or 5 [Day 1 vs. $3, p<.01$; Day 1 vs. $4, p<.05$; Day 3 vs. $5, p<.01$; Day 4 vs. $5, p<.05$ (Figure 2A)]. No significant differences were observed across saline pretreatments. Comparison of the mean total activity between pretreatment groups indicated that morphine-treated rats had significantly higher activity counts than the saline group on Day $3[t(13)=3.82, p<.01$, and Day 4 $t(13)=3.10, p<.01)]$ 
A.

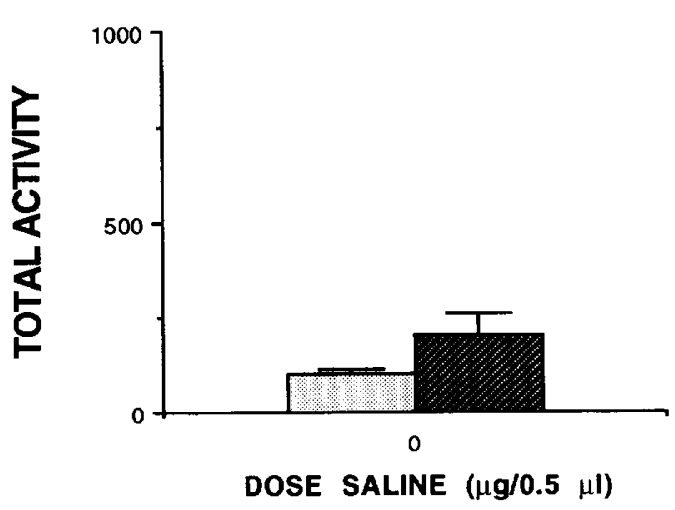

C.

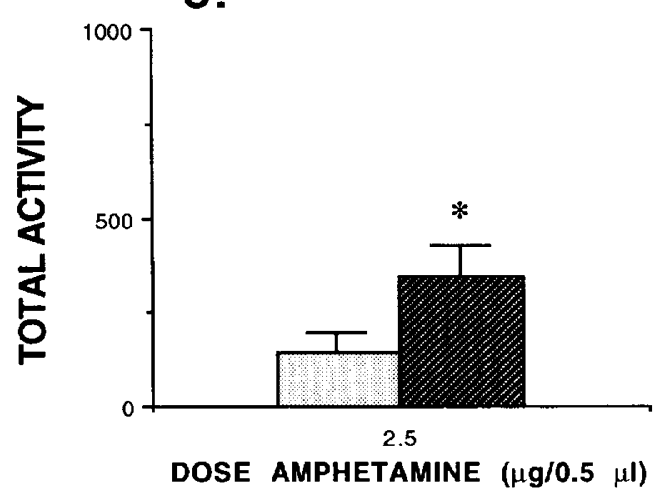

E.

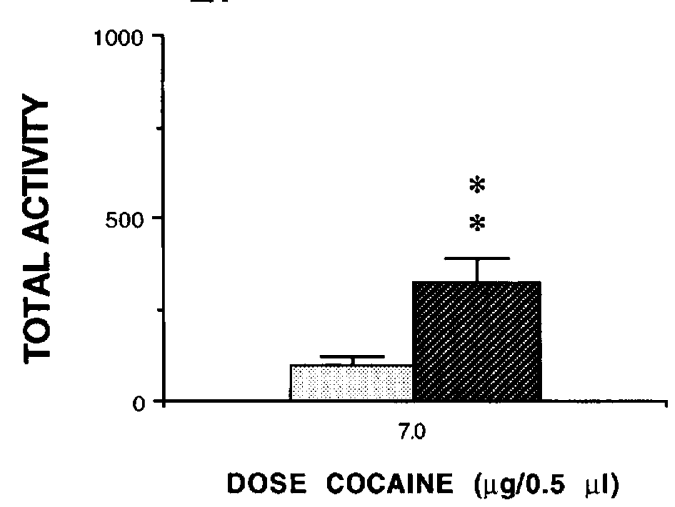

B.

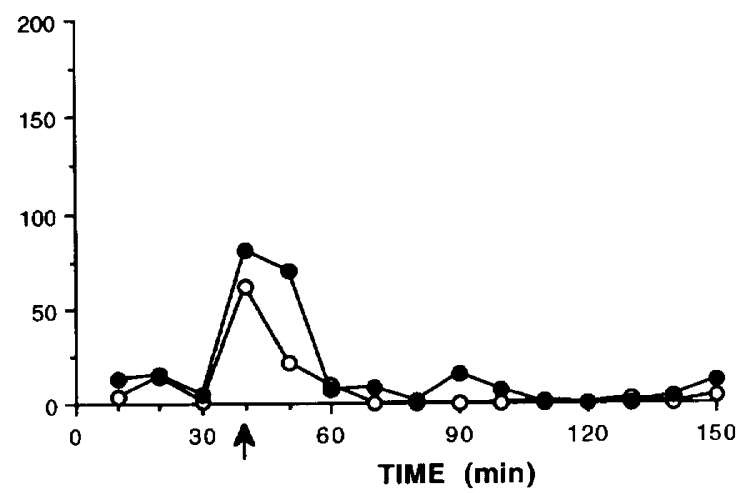

D.

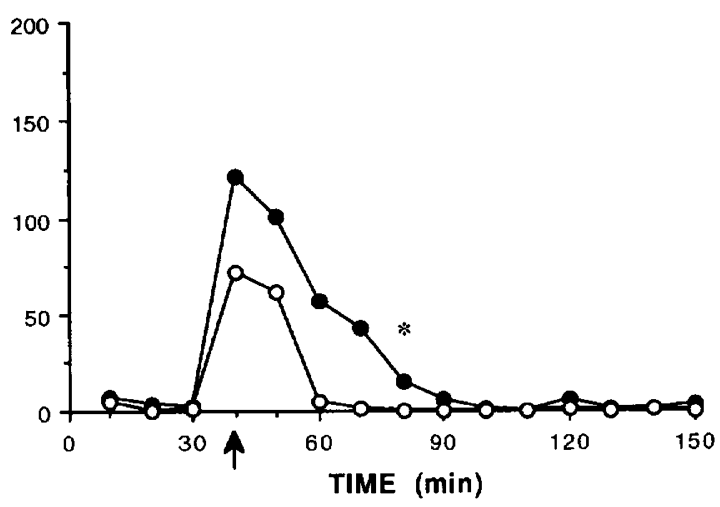

F.

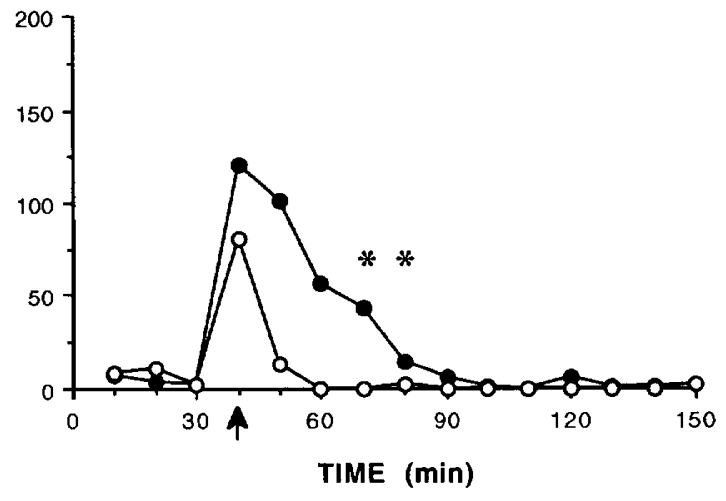

Figure 4. Effects of intraaccumbens drug treatment on motor activity in rats preexposed to systemic pretreatment with saline $(n=5)$ or morphine $(n=9)$. (A) Average locomotor response to saline challenge in animals. Grey bar, saline pretreatment. Cross-hatched bar, morphine pretreatment $(10 \mathrm{mg} / \mathrm{kg}$ IP). (B) Time course of activity during habituation and following saline (arrow) infusion. Open circles, saline pretreatment. Solid circles, morphine pretreatment $(10 \mathrm{mg} / \mathrm{kg}$ IP). (C) Mean of total activity ( 2 hours) for animals given intraaccumbens amphetamine $(2.5 \mu \mathrm{g} / 0.5 \mu \mathrm{l})$. Grey bar, saline pretreatment. Cross-hatched bar, morphine pretreatment $(10 \mathrm{mg} / \mathrm{kg} \mathrm{IP}) .{ }^{*} p<.05$, pretreatment group effect. (D) Time course for amphetamine-induced hyperactivity, following habituation (10-30 minutes). Open circles, saline pretreatment. Solid circles, morphine pretreatment (10 mg $/ \mathrm{kg} \mathrm{IP)}$. ${ }^{*} p<.05$, group-by-time interaction. (E) Mean response levels for cocaine-injected $(7.0 \mu \mathrm{g} / 0.5 \mu \mathrm{l})$ rats. Grey bar, saline pretreatment. Cross-hatched bar, morphine pretreatment $(10 \mathrm{mg} / \mathrm{kg} \mathrm{IP}) .{ }^{* *} p<.01$ group effect. (F) Activity pattern over time for cocaine microinfusion into the accumbens (arrow), which followed a habituation period. Open circles, saline pretreatment. Solid circles, morphine pretreatment $(10 \mathrm{mg} / \mathrm{kg} I \mathrm{IP}){ }^{* *} \mathrm{p}<.01$, group-by-time interaction. 
Following the morphine pretreatment regimen, IP treatment with amphetamine resulted in higher motor activity in the morphine-treated rats than in the salinetreated rats (Figure 3A). ANOVA indicated an overall effect of group $[F(1,112)=4.374, p<.05$, as well as a group-by-time interaction, $F(11,132)=2.325, p<.01$ ] This potentiating motor response lasted throughout the test period (Figure 3B). Moreover, as can be noted from Figure $2 \mathrm{~B}$, baseline activity was not different between the two pretreatment groups.

\section{Experiment 2: Effect of Systemic Morphine Pretreatment on Locomotor Activity Elicited by Intraaccumbens Amphetamine and Cocaine}

As in the first experiment, animals in Experiment 2 showed progressively enhanced motor activity over the first four morphine treatment days, which subsided on Day 5 (Figure 2B). ANOVA of the daily morphine-elicited motor effect revealed a significant effect of day $[F(4,32)=$ $4.51, p<.01]$, which was due to Day 4 activity counts relative to Days 1 and $5(p<.05)$. A significant difference across saline pretreatment days was also obtained $[F(4,16)=4.26, p<.05]$, indicating that the activity level on Day 1 was greater than on Days 4 and $5(p<.05)$. A comparison of the mean total activity across pretreatments revealed that morphine-induced locomotion was significantly greater than that elicited by saline on Day $4[t(12)=$ $2.34, p<.05$ ]. In other words, activity gradually diminished over days with saline treatment, while the response to morphine first tended to increase over days, then returned to control levels.

Systemic morphine preexposure did not significantly alter activity to intraaccumbens saline (Figure 4A-B) or augment the behavioral response to intraaccumbens amphetamine and cocaine administration (Figure 4C-F).
For the amphetamine data, a significant between-groups effect was obtained $[F(1,112)=4.83, p<0.05$; Figure $4 C-D]$. Similar results were obtained following cocaine challenge; an overall significant between-groups effect $[F(1,111)=11.44, p<0.001]$ and group-by-time interaction $[F(11,121)=7.6, p<.001]$ were found (Figure $4 \mathrm{E}-\mathrm{F})$. In addition, cocaine microinfusion also significantly elevated vertical activity (rearing) in animals previously exposed to morphine (data not shown). A between-groups effect $[F(1,112)=5.24, p<.05]$ and a group-by-time interaction for rearing $[F(11,132)=2.31, p<0.01]$ were obtained.

\section{Experiment 3: Effect of Intraaccumbens Morphine Pretreatment on Locomotor Response Following Amphetamine in the Nucleus Accumbens}

The motor-activating effect of multiple microinfusions of morphine into the nucleus accumbens remained stable over the first 3 days and was increased on the fourth pretreatment day (Figure $2 \mathrm{C}$ ). The ANOVA for the morphine data indicated a significant effect of day $[F(3,24)=$ $5.10, p<.01]$. Post hoc analysis indicated that Day 4 was different from all other treatment days (Day 1 vs. Day 4, $p<.01$; Day 2 vs. Day 4, $p<.01$; Day 3 vs. Day $4, p<$ .05). No significant differences were found across saline treatments. Comparisons of the daily treatments in the saline and morphine groups indicated that the groups differed on Days 1, 3, and 4. The unpaired Student's $t$-test indicated significant differences on Day $1[t(13)=3.45, p<$ .01 ; Day $3 t(13)=2.80, p<.05$; and on Day $4 t(13)=3.67$, $p<.01]$.

Twenty-four hours following the termination of morphine or saline pretreatment, animals received an intraaccumbens infusion of amphetamine. Although the temporal pattern was somewhat erratic, Figure 5A-B shows that animals preexposed to morphine had a
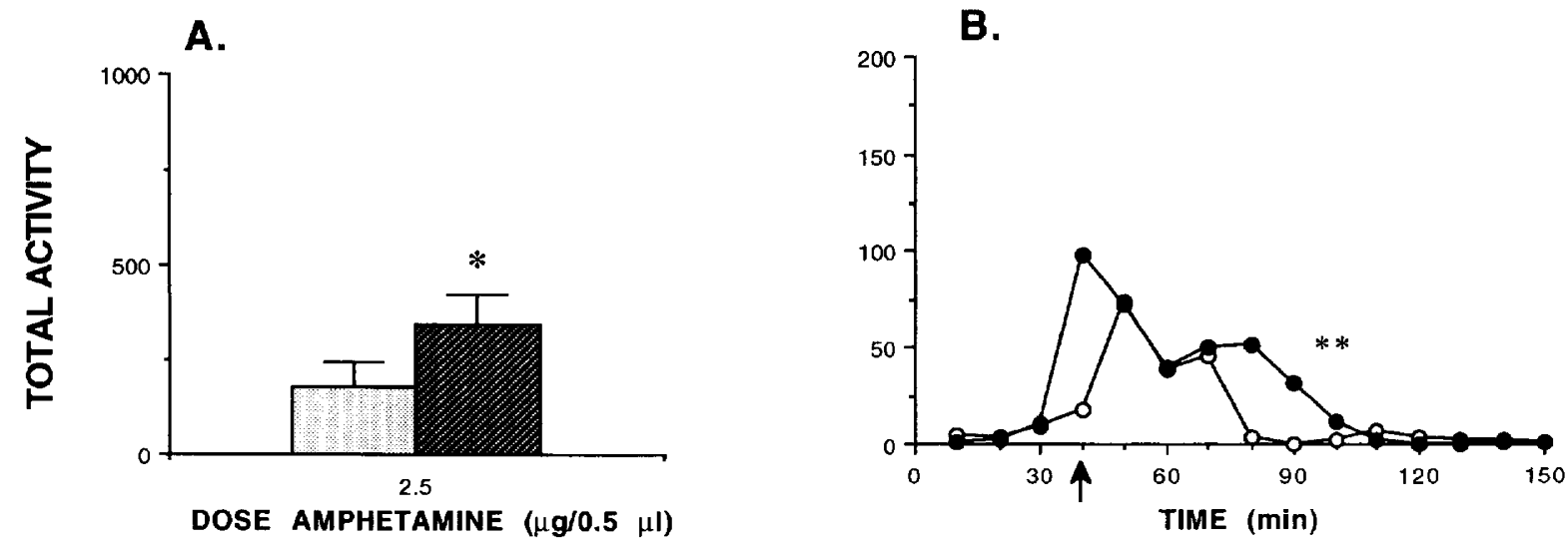

Figure 5. Total locomotor activity of rats administered intraaccumbens amphetamine $(2.5 \mu \mathrm{g} / 0.5 \mu \mathrm{l})$ following multiple saline $(n=6)$ or morphine $(n=9)(0.5 \mu \mathrm{g} / 0.5 \mu \mathrm{l} \mathrm{IC})$ microinfusion into the accumbens. (A) Average activity levels for 2 hours following amphetamine challenge. Grey bar, saline pretreatment. Cross-hatched bar, morphine pretreatment. ${ }^{*} p<.05$, pretreatment group effect. (B) Locomotor profile following nucleus accumbens infusion of amphetamine. Open circles, saline pretreatment. Solid circles, morphine pretreatment. ${ }^{* *} p<.01$, group-by-time interaction. 
greater magnitude of activation following microinfusion of amphetamine. ANOVA revealed a significant between-groups effect $[F(1,112)=5.832, p<.05$, as well as a group-by-time interaction, $F(11,132)=2.820, p<.011$.

\section{DISCUSSION}

The present results demonstrate that prior exposure to morphine sensitizes animals to amphetamine or cocaine and that the nucleus accumbens is a neural substrate involved in the induction of this phenomenon. The findings in Experiment 1, that repeated systemic administration of morphine results in higher behavioral response to amphetamine, are in agreement with previous reports (Kalivas 1985; DuMars et al. 1988; Vezina et al. 1989). In Experiments 2 and 3 , we report novel findings regarding the role of the nucleus accumbens in this behavioral phenomenon. Following intermittent systemic morphine exposure, local injection of amphetamine or cocaine into the nucleus accumbens resulted in a potentiated locomotor response. This finding indicates that the reactivity of the accumbens to drugs that augment synaptic DA has been altered by preexposure to systemic morphine. Although environment-specific conditioning may have contributed to the potentiation, a conditioned response is not solely responsible for the observed sensitized locomotor response, as vehicle challenge did not result in significantly potentiated locomotion. However, the tendency toward conditioned activity is apparent in Figure 4B.

In regimens that have employed systemic injections of opiates or stimulants, it has been clearly shown that alterations take place at the level of dopamine cell bodies, in the ventral tegmental area (Vezina et al. 1987; DuMars et al. 1988; Stewart and Vezina 1989). In consideration of the present findings, it is possible that multiple systemic morphine injections also induce intrinsic alterations in the nucleus accumbens. One possible underlying mechanism is an enhancement of morphine-induced dopamine release. Opiates increase dopamine release acutely (Di Chiara and Imperato 1988; Pentney and Gratton 1991), and several studies have reported higher dopamine release following repeated opiate treatment (Kalivas and Duffy 1988, 1990). However, at the level of the accumbens, opiate behavioral effects are thought to be primarily dopamine-independent (Pert and Sivit 1977; Kalivas et al. 1983; Stinus et al. 1985; Vaccarino et al. 1986). Therefore, alteration in dopamine release probably does not entirely explain morphine-elicited facilitation of the stimulant locomotor response, although it could be a contributing factor.

A second possible component of opiate-dopamine interactions in the nucleus accumbens may involve intraneuronal signal transduction mechanisms, as both opiates and psychostimulants exert their effects through the cyclic adenosine manophasphate (AMP) secondmessenger system (Nestler 1994). Early theories of opiate addiction and withdrawal implicated the cyclic adenosine monophosphate (AMP) system (Collier and Roy 1974; Law et al. 1981). For example, it was initially observed that acute morphine exposure downregulated cyclic AMP. More recent biochemical data show that chronic exposure to opiates and psychostimulants induces alterations in the cyclic AMP second-messenger system (Tirone et al. 1988; Johnson and Fleming 1989; Guitart and Nestler 1989; Nestler et al. 1990; De Vries et al. 1991; Terwilliger et al. 1991; Van Vliet et al. 1992). Moreover, direct upregulation of the cyclic AMP system in the mesolimbic dopamine system, via treatment with selective bacterial toxins, has been demonstrated to potentiate the motor response to stimulants (Steketee and Kalivas 1991; Cunningham and Kelley 1993). Further evidence that the reinforcing effects of both opiates and stimulants depend on common intracellular pathways is provided by the finding that pertussis-toxin-induced inactivation of inhibitory $G$ proteins in the accumbens reduces self-administration of these drugs (Self et al. 1994). Thus, the enhanced response observed in the present experiments could be due to an altered regulation of these signaling pathways.

The observation in Experiment 2, that prior systemic exposure to morphine results in a facilitation of intraaccumbens amphetamine-induced motility, further implicates the nucleus accumbens in the expression of behavioral sensitization. Moreover, we propose a direct involvement of this region in the development of this phenomenon as well. In experiment 3 , intermittent localized injections of morphine into the nucleus accumbens also resulted in a small, yet significant, increase in amphetamine-induced locomotion. It is noteworthy that the magnitude of elevation was smaller than that observed in either Experiments 1 or 2 , in which morphine was administered systemically. It is probable, therefore, that the nucleus accumbens may only contribute to the development of sensitization, in conjunction with the ventral tegmental area and perhaps other forebrain sites. In summary, intracellular mechanisms in the nucleus accumbens may play a role in both the development and expression of opiate-dopamine cross-sensitization. Further work is needed to address more precisely what specific molecular changes underlie these behavioral observations, their duration, and their relation to long-term phenomena such as relapse to drug use.

\section{ACKNOWLEDGMENTS}

Support for this research was provided by grant DA04788 from the National Institute on Drug Abuse (AEK) and an American Psychological Association Minority Fellowship predoctoral award (STC). These studies were conducted as part of 
the doctoral dissertation of STC, at the Department of Psychology, Northeastern University, Boston, MA.

\section{REFERENCES}

Bilsky EJ, Montegut MJ, Delong CL, Reid LD (1992): Opioidergic modulation of cocaine conditioned place preferences. Life Sci 50:PL-85-90

Bouyer JJ, Park DH, Joh TH, Pickel VM (1984): Chemical and structural analysis of the relation between cortical inputs and tyrosine hydroxylase-containing terminals in the rat neostriatum. Brain Res 302:267-275

Bruning JL, Kintz BL (1987): Computational Handbook of Statistics, Glenview, IL, Scott, Foresman

Cador M, Bjijou Y, Stinus L (1995): Evidence of complete independence of the neurobiological substrates for the induction and expression of behavioral sensitization to amphetamine. Neuroscience 65:385-396

Collier HJ, Roy AC (1974): Morphine-like drugs inhibit the stimulation by E prostaglandins of cyclic AMP formation by rat brain homogenate. Nature 248:24-27

Cunningham ST, Kelley AE (1992): Evidence for opiatedopamine cross-sensitization in nucleus accumbens: Studies of conditioned reward. Brain Res Bull 29:675-680

Cunningham ST, Kelley AE (1993): Hyperactivity and sensitization to psychostimulants following cholera toxin infusion into the nucleus accumbens. J Neurosci 13:2342-2350

De Vries TJ, Van Vliet BJ, Hogenboom F, Wardeh G, Van der Laan JW, Mulder AH, Schoffelmeer ANM (1991): Effect of chronic prenatal morphine treatment on $\mu$-opioid receptor-regulated adenylate cyclase activity and neurotransmitter release in rat brain slices. Eur J Pharmacol 208:97-104

Di Chiara G, Imperato A (1988): Drugs abused by humans preferentially increase synaptic dopamine concentrations in the mesolimbic system of freely moving rats. Proc Natl Acad Sci USA 85:5274-5278

DuMars LA, Rodger LD, Kalivas PW (1988): Behavioral cross-sensitization between cocaine and enkephalin in the A10 dopamine region. Behav Brain Res 27:87-91

Goodman RR, Snyder SH, Kuhar MJ, Young WS (1980): Differentiation of delta and mu opiate receptor localizations by light microscopic autoradiography. Proc Natl Acad Sci USA 77:4469-4473

Guitart X, Nestler EJ (1989): Identification of morphine- and cyclic AMP-regulated phosphoproteins (MARPPs) in the locus coeruleus and other regions of rat brain: Regulation by acute and chronic morphine. J Neurosci 9:4371-4387

Johnson RP, Sar M, Stumpf WE (1980): A topographic localization of enkephalin on the dopamine neurons of the rat substania nigra and ventral tegmental area demonstrated by combined histofluorescence-immunohistochemistry. Brain Res 194:566-571

Johnson SM, Fleming WW (1989): Mechanisms of cellular adaptive sensitivity changes: Applications to opioid tolerance and dependence. Pharmacol Rev 41:435-488

Kalivas PW (1985): Interactions between neuropeptides and dopamine neurons in the ventromedial mesencephalon. Neurosci Biobehav Rev 9:573-587
Kalivas PW, Duffy P (1988): Effects of daily cocaine and morphine treatment on somatodendritic and terminal field dopamine release. J Neurochem 50:1498-1504

Kalivas PW, Duffy P (1990): Effect of acute and daily enkephalin treatments on extracellular dopamine in the nucleus accumbens. J Neurosci 10:2940-2949

Kalivas PW, Stewart J (1991): Dopamine transmission in the initiation and expression of drug- and stress-induced sensitization of motor activity. Brain Res Rev 16:223-244

Kalivas PW, Widerlov E, Stanley D, Breese G, Prange AJ, Jr (1983): Enkephalin action on the mesolimbic system: A dopamine dependent and a dopamine independent increase in locomotor activity. J Pharmacol Exp Ther 227:229-237

Kalivas PW, Taylor S, Miller JS (1985): Sensitization to repeated enkephalin administration into the ventral tegmental area of the rat. I. Behavioral characterization. J Pharmacol Exp Ther 235:537-543

Law PY, Wu J, Koehler JE, Loh HH (1981): Demonstration and characterization of opiate inhibition of the striatal adenylate cyclase. J Neurochem 36:1834-1846

Lett BT (1989): Repeated exposures intensify rather than diminish the rewarding effects of amphetamine, morphine and cocaine. Psychopharmacologia (Berlin): 98:357-362

Mansour A, Kachaturian H, Lewis ME, Akil $\mathrm{H}$ and Watson SJ (1987): Autoradiographic differentiation of $\mathrm{mu}$, delta, and kappa opioid receptors in the rat forebrain and midbrain. J Neurosci 7: 2445-2464

Nestler EJ (1994): Molecular neurobiology of drug addiction. Neuropsychopharmacology 11:77-87

Nestler EJ, Tallman (1988): Chronic morphine increases cyclic AMP-dependent protein kinase activity in the rat locus ceruleus. Mol Pharmacol 33:127-132

Nestler EJ, Terwilliger RZ, Walker JR, Sevarino KA, Duman RS (1990): Chronic cocaine treatment decreases levels of the $G$ protein subunits Gia and Gio in discrete regions of rat brain. J Neurochem 55:1079-1082

Paulson PE, Robinson TE (1991): Sensitization to systemic amphetamine produces an enhanced locomotor response to a subsequent intra-accumbens amphetamine challenge in rats. Psychopharmacology 104:140-141

Paulson PE, Robinson TE (1995): Amphetamine-induced time-dependent sensitization of dopamine neurotransmission in the dorsal and ventral striatum: A microdialysis study in the rat. Synapse 19:56-65

Pellegrino LJ, Cushman AF (1967): A Stereotaxic Atlas of the Rat Brain, New York, Appleton-Century-Crofts

Pentney RJW, Gratton A (1991): Effects of local delta and mu opioid receptor activation on basal and stimulated dopamine release in striatum and nucleus accumbens of rat: An in vivo electrochemical study. Neuroscience 45:95-102

Pert A, Sivit C (1977): Neuroanatomical focus for morphine and enkephalin-induced hypermotility. Nature 265:645646

Pickel VM, Sumal KK, Beckley SC, Miller RJ, Reis DJ (1980): Immunocytochemical localization of enkephalin in the neostriatum of rat brain: A light and electron microscopic study. J Comp Neurol 189:721-740

Pierce RC, Kalivas PW (1995): Amphetamine produces sensitized increases in locomotion and extracellular dopa- 
mine preferentially in the nucleus accumbens shell of rats administered repeated cocaine. J Pharmacol Exp Ther 275:1019-1029

Pilotte NS, Sharpe LG, Rountree SD, Kuhar MJ (1996): Cocaine withdrawal reduces dopamine transporter binding in the shell of the nucleus accumbens. Synapse 22:87-92

Self DW, Terwilliger RZ, Nestler EJ, Stein L (1994): Inactivation of $\mathrm{Gi}$ and Go proteins in nucleus accumbens reduces both cocaine and heroin reinforcement. J Neurosci 14:6239-6247

Stewart J, Vezina P (1987): Environment-specific enhancement of the hyperactivity induced by systemic or intraVTA morphine injections in rats preexposed to amphetamine. Psychobiology 15:144-153

Stewart J, Vezina P (1989): Microinjections of Sch-23390 into the ventral tegmental area and substantia nigra pars reticulata attentuate the development of sensitization to the locomotor activating effects of systemic amphetamine. Brain Res 495:401-406

Stinus L, Winnock M, Kelley AE (1985): Chronic neuroleptic treatment and mesolimbic dopamine denervation induce behavioural supersensitivity to opiates. Psychopharmacology 85:323-328

Terwilliger RZ, Beitner-Johnson D, Sevarino KA, Crain SM, Nester EJ (1991): A general role for adaptations in Gproteins and the cyclic AMP system in mediating the chronic actions of morphine and cocaine on neuronal function. Brain Res 548:100-110
Tirone F, Viganó A, Groppetti A, Parenti M (1988): Effects of the desensitization by morphine of the opiate-dependent adenylate cyclase system in the rat striatum on the activity of the inhibitory regulatory $\mathrm{G}$ protein. Biochem Pharmacol 37:1039-1044

Vaccarino FJ, Amalric M, Swerdlow NR, Koob GF (1986): Blockade of amphetamine but not opiate-induced locomotion following antagonism of dopamine function in the rat. Pharmacol Biochem Behav 24:61-65

Van Vliet BJ, Dotman CH, Wardeh G, Mulder AH, Schoffelmeer ANM (1992): Differential effects of chronic agonist administration on $\mu$-opioid receptor- and muscarinic receptor-regulated adenylate cyclase in rat striatal slices. Life Sci 51:PL-89-94

Vezina P, Stewart J (1989): The effect of dopamine receptor blockade on the development of sensitization to the locomotor activating effects of amphetamine and morphine. Brain Res 499:108-120

Vezina P, Stewart J (1990): Amphetamine administered to the ventral tegmental area but not to the nucleus accumbens sensitizes rats to systemic morphine: Lack of conditioned effects. Brain Res 516:99-106

Vezina P, Kalivas PW, Stewart J (1987): Sensitization occurs to the locomotor effects of morphine and the specific $\mu$-opioid receptor agonist, DAGO, administered repeatedly to the ventral tegmental area but not to the nucleus accumbens. Brain Res 417:51-58

Vezina P, Giovino AA, Wise RA, Stewart J (1989): Environment-specific cross-sensitization between the locomotor activating effects of morphine and amphetamine. Pharmacol Biochem Behav 32:581-584 